\section{P07.15 REABILITY AND VALIDITY ON BACTERIAL VAGINOSIS (BV) SCREENING AMONG SEXUAL WORKERS - BATURRADEN, BANYUMAS DISTRIC, CENTRAL JAVA, INDONESIA 2014}

'Leyna Chunaifa*, ${ }^{2}$ B Rahayujati, ${ }^{3}$ A Pratiwi. ${ }^{1}$ Field Epidemiology and Training Program (FETP), GadjahMada University, Indonesia; ${ }^{2}$ Health Department of Kulonprogo District, Yogyakarta Special Region Province, Java, Indonesia; ${ }^{3}$ Disease Control and Environmental Health, Health Department of Banyumas, Central Java Province, Indonesia

\subsection{6/sextrans-2015-052270.33}

Introduction Prevalence of Bacterial Vaginosis (BV) in various countries around the world is quite high and the highest prevalence is found in female sex workers (FSW). Resulting interference of BV epithelial vaginal infection, disturbsbalance of normal flora of the vagina and changesacidity $(\mathrm{pH})$, which could be a base for increased risk to HIV infection. Early BV detection among FSW is recommended for early treatment to prevent other serious infections. Screening was conducted to detect BV, calculate the prevalence and evaluate the medical staff of STD's Program.

Methods A crossectional study was implemented in December 2014. Subjects were sex workers in Banyumas District, Central Java. Amsel criteria were used for diagnostic test and Hay/Ison criteria as a gold standard.

Results There 99 women out of 200 sex worker in Baturraden were screened. Results of screening of BV as perAmsel criteria are 37 people (38\%) and gold standard are 43 people (43\%) positive for BV. The loss of acidity was found in most of them $(78 \%)$ as an indicator with the highest level of agreement (97\%). The fishy smell indicator using whiff test on were the lowest level of agreement (74\%). Reability of the examination between doctors is optimum (89\%). Realibility of clue cell indicators using microscopic examination between analyst on the health centre with hospital is still limited (56\%). The validity of Amsel criteria compared with Hay/Ison criteria were optimum ( $\mathrm{Sn}=$ $89 \%, \mathrm{Sp}=72 \%, \mathrm{PPV}=81 \%, \mathrm{NPV}=84 \%$ ).

Conclusion Prevalence of BV among subjects were 43\%. Amsel criteria can be used for screening method because it has good sensitivity and specificity to determine BV. The agreement between Health Centre Analyst and Hospital need to be improved $(<80 \%)$. We recommend Banyumas Health Department to conduct workshop and training for laboratory staff for microscopic examination.

Disclosure of interest statement This study is my field project as a FETP Trainee that are funded by FETP UGM. No funding were received for this study.

\section{P07.16 THE IMPORTANCE OF ATOPOBIUM VAGINAE IN BACTERIAL VAGINOSIS-ASSOCIATED BIOFILM}

1,2,3 $\mathrm{L}$ Hardy* ${ }^{*}{ }^{1} \mathrm{~V}$ Jespers, ${ }^{3} \mathrm{~S}$ Abdellati, ${ }^{3} \mathrm{I}$ De Baetselier, ${ }^{4} \mathrm{~L}$ Mwambarangwe, ${ }^{4} \mathrm{~V}$ Musengamana, ${ }^{4,5} \mathrm{~J}$ van de Wijgert, ${ }^{2} \mathrm{M}$ Vaneechoutte, ${ }^{3} \mathrm{~T}$ Crucitti. ${ }^{1}$ Unit of Epidemiology and Control of HIVISTD, Department of Public Health, Institute of Tropical Medicine, Antwerp, Belgium; 'Laboratory Bacteriology Research, Faculty of Medicine \& Health Sciences, University of Ghent, Belgium; ${ }^{3}$ HIVISTI Reference Laboratory, Department of Clinical Sciences, Institute of Tropical Medicine, Antwerp, Belgium; ${ }^{4}$ Rinda Ubuzima, Kigali, Rwanda; Institute of Infection and Global Health, University of Liverpool, Liverpool, UK

\subsection{6/sextrans-2015-052270.332}

Introduction In case of bacterial vaginosis (BV), lactobacilli are outnumbered by anaerobic bacteria. These bacteria have been described to form a polymicrobial biofilm ("clue cells") attached to the vaginal epithelium, possibly explaining the decreased sensitivity to antibiotic treatment and the frequent chronicity of BV. A better understanding of this biofilm may contribute to more precise delineation, and consequently to better diagnosis and treatment of BV. We used Fluorescence In Situ Hybridization (FISH) to study the presence of Atopobium vaginae (Av) and Gardnerella vaginalis (Gv) biofilm, in relation to the status of the vaginal microbiome (according to Nugent score).

Methods Duplicates of 461 vaginal slides of 120 participants, participating in a contraceptive vaginal ring trial in Rwanda, were evaluated according to Nugent score after Gram staining and by FISH with species-specific probes for Av and Gv.

Results In the majority of samples $(59.6 \%)$ with Nugent score 7-10 (BV diagnosis), a Gv+Av biofilm was visualised by FISH. In these BV samples, 7\% had no Gv and Av present, in 9\% Gv and/or Av was present but only planktonic, $18.6 \%$ had Gv biofilm but no Av present and 5.8\% Gv biofilm with Av planktonic only. When Av and/or Gv were planktonic in the vagina and not part of a biofilm, the Nugent score was low, defining a healthy vaginal microbiome. However the probability of having a disturbed vaginal microbiome (Nugent 7-10) was increased ( $\mathrm{p}<$ 0.001 ) when a biofilm was visualised with FISH. Moreover, the probability for having a Nugent score of $7-10$ was increasing when A. vaginae was part of the biofilm ( $\mathrm{p}<0.001)$.

Conclusion Our study focusing on Gv and Av, shows that these are two major players in a polymicrobial condition. It confirms the importance of Gv-biofilm in BV and strongly indicates that Av plays an important role in BV-associated biofilm.

Disclosure of interest statement This work was supported by European and Developing Countries Clinical Trials Partnerships (EDCTP), by Combined Highly Active Anti-Retroviral Microbicides (CHAARM) and by Dormeur Investment Service. No pharmaceutical grants were received in the development of this study.

\section{P07.17 CHANGES OF BIOMARKERS IN A MSM HIV INFECTION INDICATE THE REQUIREMENTS OF BOTH ANTIGEN AND ANTIBODY TESTS FOR EARLY DIAGNOSIS}

${ }^{1} \mathrm{~W} \mathrm{Gu}^{*},{ }^{2} \mathrm{Y} \mathrm{Hu},{ }^{1} \mathrm{~W}$ Hu, ${ }^{2} \mathrm{~B}$ Xu. ${ }^{1}$ Shanghai Dermatology Hospital, Shanghai, 200050, China; ${ }^{2}$ School of Public Health, Fudan University, Shanghai 200032, China

\subsection{6/sextrans-2015-052270.333}

Background Early diagnosis of human immunodeficiency virus (HIV) infections has significant impact in HIV controls. This case report aimed to examine changes of biomarkers in an acute HIV infection in a man who had sex with men (MSM), and to suggest laboratory tests for early detection of HIV infections.

Methods The patient presented himself to a specialised hospital. Information on sexual activities, symptoms and signs were collected during the consultation. Repeated measurements of HIV viral-load, p24 antigen-antibody complex, and lymphocyte subsets were undertaken. Tests for HIV genotypes and drug resistance were also conducted.

Results The patient, a MSM, sought medical care 8 days after the onset of low fever and sore throat. The last unprotected MSM sex activity occurred 20 days prior to the onset of the symptoms. Physical examination revealed periodontitis and torso rash. The p24 antigen was positive on the $1^{\text {st }}$ visit and titers declined to undetectable 10 days after the $1^{\text {st }}$ visit. HIV antibody was absent until 10 days after the $1^{\text {st }}$ visit, and confirmatory test (Western Blot) was negative until 20 days after the 1st visit. 